\title{
EFEITOS DA HERANÇA PSÍQUICA NA OPÇÃO PELA NÃO CONSTRUÇÃO DO VÍNCULO AMOROSO
}

\author{
Sandra Aparecida Serra Zanetti \\ Psicóloga, mestre e doutoranda do programa de pós-graduação em psicologia clínica da \\ Universidade de São Paulo.
}

Isabel Cristina Gomes

Professora Titular do Instituto de Psicologia da Universidade de São Paulo.

\begin{abstract}
Resumo
O presente artigo objetiva demonstrar a influência e importância da herança psíquica familiar na opção pela não construção de um vínculo amoroso compromissado, a partir da análise de um caso. Esse artigo baseia-se numa pesquisa mais ampla que visou compreender esse tipo de opção pelo viés sociocultural, econômico e psíquicogeracional, cujos resultados evidenciaram a dimensão deste último fator psíquico influenciando esse tipo de escolha.
\end{abstract}

Palavras-chave: transmissão psíquica entre gerações, psicanálise, amor.

\section{EFFECTS OF PSYCHIC HERITAGE IN THE OPTION OF NOT BUILDING THE LINK OF LOVE}

\begin{abstract}
This article aims to demonstrate the influence and importance of psychic heritage familiar in the option of not building a committed loving relationship, based on the analysis of a case. This article is based on a broader research that aimed to understanding this kind of option by the sociocultural, economic and psychogenerational references, whose results showed the importance of this psychic factor influencing this kind of choice.

Keywords: psychic transmission between generations, psychoanalysis, love.
\end{abstract}

\section{EFECTOS DE LA HERENCIA PSÍQUICA EN LA OPCIÓN DE NO CONSTRUIR EL VÍNCULO DEL AMOR}

\begin{abstract}
Resumen
En este artículo se pretende demostrar la influencia y la importancia de la herencia psíquica familiar en la opción de no construir una relación de compromiso amoroso, basado en el análisis de un caso. Este artículo se basa en una investigación más amplia que pretendía comprender este tipo de opción a través del referencial sociocultural, económico y psico-generacional, cuyos resultados mostraron la magnitud del factor psíquico influyendo en este tipo de elección.
\end{abstract}

Palabras clave: transmisión psíquica entre las generaciones, psicoanálisis, amor. 


\section{INTRODUÇÃO}

O presente artigo pretende demonstrar o modo como a herança psíquica pode influenciar na opção pela não construção de um vínculo amoroso compromissado, a partir da análise de um caso. A transmissão da vida psíquica é um conceito psicanalítico que considera como herança familiar também aquilo que se herda dentro de uma cadeia de gerações precedentes em termos de vida psíquica, que pôde ou não ser elaborada e transformada. Contudo, importante ressaltar, este estudo insere-se no âmbito de uma pesquisa mais ampla ${ }^{1}$, que pretendeu compreender a construção subjetiva de adultos que optam por não se vincular amorosamente de maneira compromissada em meio às condições socioculturais e econômicas contemporâneas de existência e a herança psíquica familiar. Ou seja, estamos enfatizando esta vertente do trabalho total porque foi possível perceber o quanto a herança psíquica é um viés importante para se compreender esse tipo de opção amorosa; o que poderá ser visto por meio do caso selecionado, bastante ilustrativo desta influência.

Para tanto, nesta introdução serão discutidos os aportes teóricos em que nos baseamos para a análise interpretativa do caso, bem como um levantamento bibliográfico que ressalta e assegura a importância deste tipo de pesquisa, principalmente para o avanço da teoria e da clínica psicanalíticas.

\section{Psicanálise, Pesquisas e a Herança Psíquica}

Quando Freud (1921/2006), em sua obra Psicologia de Grupo e a Análise do Ego destacou a presença da intersubjetividade na constituição psíquica do sujeito, foi também o conceito de transmissão psíquica que passou a ser incorporado à psicanálise, para Kaës (2001). Nesse trabalho, é possível dizer, segundo esse autor, "que Freud inventa uma genealogia da psique, de suas instâncias e de suas ramificações interpsíquicas" (Kaës, 2001, p. 10).

Os pontos nodais da questão da transmissão estão no cerne das interrogações de Freud, segundo Kaës (2001), inaugurando a existência de um sujeito da herança, que está dividido "como o sujeito do inconsciente, entre a necessidade 'de ser um fim para si mesmo' e de ser 'o elo de uma cadeia à qual está sujeito sem a participação da vontade'" (Kaës, 2001, p. 11). O grupo

${ }_{1}$ Tese de doutorado em andamento no departamento de Psicologia Clínica do Instituto de Psicologia da Universidade de São Paulo. 
precede o sujeito do grupo, e, portanto, o sujeito deve servi-lo, mas do qual também pode esperar tirar benefícios.

Kaës (2001) considera que a identificação é o principal mecanismo envolvido no processo da transmissão psíquica entre gerações. Indica que, nesse processo, transmite-se também "aquilo que ampara e assegura as continuidades narcísicas, a manutenção dos vínculos intersubjetivos, a conservação e complexidade das formas e da vida: ideais, mecanismos de defesa, identificações, certezas, dúvidas" [itálicos nossos] (p. 9). Este tipo de transmissão leva o nome de transmissão psíquica geracional e envolve um trabalho de ligações e transformações entre as gerações. De acordo com Granjon (2001),

Tal trabalho permite que o indivíduo se vincule a um grupo, esse grupo a outro, num encadeamento de gerações, é o que dá a noção de "pertencimento" e o que permite a construção da própria subjetividade, dentro de um processo de transformação, de criação, do material que é transmitido. É por esse processo que o indivíduo também se torna, por um lado, autor e por outro proprietário de sua herança. Em última instância, é algo que representa e permeia a história pessoal, familiar e da própria civilização. (p. 24).

Pesquisas centradas em compreender a transmissão psíquica entre as gerações (Haesler, 1992; Levine, 1982; Puget, Kaës et al, 1989; Stern, 1986; Schacht, 1977) sugerem uma urgência ou uma espécie de impulso para transmitir, sob o efeito de um imperativo psíquico incoercível (Kaës, 2001). Essa necessidade, segundo o autor, "é o resultado de exigências pulsionais inconscientes, nas quais prevalecem ora coerções narcísicas de conservação e de continuidade da vida psíquica, ora as do Ideal do Ego e do Superego, mais precisamente a transmissão dos interditos fundamentais" (p. 16).

A transmissão da continuidade evolutiva de uma geração a outra, como mostra Granjon (2001), permite que cada uma não parta do "zero". Esta autora também considera a existência de uma urgência imperiosa neste processo, pois uma geração não pode existir sem aquela que a precede e a vida deve ser transmitida. Deste modo, o projeto do grupo familiar é

transmitir a herança psíquica, adquirida e fundadora de cada um e perpetuar-se dando vida para além dos mortos. (...) Neste contexto, o lugar que cada um ocupa no grupo se relaciona ao lugar na cadeia de gerações, que se relaciona com aqueles que não mais existem e que ele deve gerir, adquirir e transmitir (Granjon, 2001, p. 20).

Contudo, como propõem Passos (2007), Magalhães e Féres-Carneiro (2004), como pensar a formação dos vínculos intersubjetivos no processo de 
transmissão geracional em uma cultura que privilegia individualidades? Refletindo acerca desta temática é que a nossa pesquisa foi desenvolvida. Pensamos inicialmente que a opção pela não construção de um vínculo amoroso compromissado estava vinculada às condições socioculturais e econômicas de existência atuais, mas descobrimos que não apenas. Algumas pesquisas apontam que para compreender a construção dos vínculos, é importante também o estudo de aspectos relativos à constituição subjetiva em meio à herança psíquica familiar.

Passos (2007) em seu artigo A constituição dos laços na família em tempos de individualismo percebe que a fragilidade com que são formados os laços atualmente, a falta de compromisso, as dispersões nas relações humanas e as relações de caráter inconsistentes da sociedade têm interferido na dinâmica da família contemporânea. Estes fatores, para ela, repercutem no contexto intersubjetivo do grupo familiar, interferindo na configuração dos laços afetivos no espaço da família - origem dos demais laços sociais - e, consequentemente, no processo de subjetivação.

No entanto, para a autora citada, a constituição do sujeito, segundo a psicanálise, implicaria ainda na "assunção de uma dívida face ao outro, sem o qual não teríamos condições de existir" (Birman, 1977 citado por Passos, 2007, p. 120). Esta dívida "se impõe muito antes do que podemos supor: vem dos nossos ancestrais, atravessa gerações e instaura a transmissibilidade psíquica como primeiro eixo na relação intersubjetiva eu-outro, que tem a família como contexto e suporte" (Passos, 2007, p. 120). Ou seja, esta autora ressalta a importância da constituição subjetiva a partir dos laços familiares.

Féres-Carneiro (2005), num estudo que buscou entender a relação entre a conjugalidade dos pais e o projeto de casamento dos filhos, verificou que o lugar que o casamento ocupa no projeto de vida dos indivíduos participantes parece estar relacionado com o modo como se apropriam de sua herança familiar e com o discernimento acerca dos aspectos da conjugalidade dos pais que influenciam em suas escolhas. Percebeu, por exemplo, que na maioria dos casos em que os jovens apresentavam um discurso em que se percebia uma recusa na percepção da influência da conjugalidade dos pais em seus projetos de vida, tais pais haviam sido avaliados como tendo uma conjugalidade muito insatisfatória. A autora considera que esse resultado evidencia o quanto o "não enfrentamento pelos pais de seus conflitos conjugais e a manutenção de uma relação conjugal 
insatisfatória interferem no processo de identificação e de diferenciação dos filhos e, consequentemente, na possibilidade de elaborar projetos de vida mais autônomos" (p. 96).

Diante da mesma problemática, Magalhães e Féres-Carneiro (2004) procuram compreender o processo de "transmissão psíquica" na contemporaneidade, assinalando a necessidade de se considerar o contexto sociocultural e econômico atual, marcado por um acelerado processo de mudanças, no qual "as ligações afetivas tendem a ser pouco duradouras, e os investimentos de grande risco, em que a instabilidade é um imperativo" (p. 244). Decorrentes deste contexto, as autoras destacam a existência de processos de "dessimbolização", de falta de referências estáveis, de ausência de figuras de lei, de desvinculação, de rupturas e de descontrole, através dos quais os laços intersubjetivos se afrouxam. No entanto, apoiadas em Kaës (1993), percebem que existe a necessidade

\begin{abstract}
da precedência por um outro e por mais de um outro no processo de subjetivação e, com base na obra freudiana, evidencia a importância da intersubjetividade. Coloca-se a centralidade do espaço intersubjetivo e, mais especificamente, do espaço e do tempo geracional. O sujeito não é auto-engendrado, e o trabalho psíquico de constituição da subjetividade implica a metabolização da herança no confronto com o outro que transmite (Magalhães \& Féres-Carneiro, 2004, p. 244).
\end{abstract}

Portanto, será dentro desta abordagem, levando em consideração a herança psíquica e a relação que o sujeito estabelece com a mesma, com aquilo que o antecedeu, sua capacidade de apropriação e de elaboração deste material, que procuraremos entender a opção pela não construção de um vínculo amoroso compromissado.

\title{
O processo de Transmissão da Vida Psíquica
}

De acordo com Kaës (2009), as práticas da transmissão nasceram com a humanidade e fazem a humanidade. Dentre elas estão as transmissões de saberes, de técnicas, de mitos, de crenças, mas aquelas que nos interessam mais particularmente, ele sublinha, são as de conteúdo e processos psíquicos.

Este autor compreende o "singular" como o espaço psíquico individualizado que contém a marca específica da estrutura, da história e da subjetividade singular: "sua organização pulsional, suas fantasias secundárias, seus mecanismos de defesa e seus conteúdos recalcados e clivados, suas 
identificações, suas relações de objeto, em suma, o que singulariza o desejo do inconsciente" (Kaës, 2011, p. 54). Entretanto, uma parte do que é singular sempre se origina naquilo que o sujeito herdou, adquiriu e transformou ou no que permaneceu com ele sem transformação. Neste processo, as alianças inconscientes proporcionam o processo de subjetivação, pois ao procurar-se diferenciar dessas influências, o sujeito irá transformá-las, de forma criativa, em algo que lhe pertença realmente.

O que se transmite psiquicamente, para Kaës (2005), "são essencialmente configurações de objetos psíquicos, isto é, objetos munidos de seus vínculos com aqueles que precedem cada sujeito" (p. 128). Isto faz da pré-história do sujeito não somente aquilo que o sustenta e garante pelo positivo, "as continuidades narcísicas e objetais, a manutenção dos vínculos intersubjetivos, as formas e os processos de conservação e complexidade da vida" (p. 128), mas também pelo negativo: aquilo que não pôde ser retido, contido, que não é lembrado, o que "não encontra inscrição na psique dos pais e vem depositar-se ou enquistar-se na psique da criança: a falta, a doença, o crime, os objetos desaparecidos sem traço nem memória; para os quais um trabalho de luto não pôde ser realizado" (p. 128). Nesse caso, o autor considera que o processo de projetar no outro, ou depositar nele, o impensado, as falhas, poderia ser compreendido como o aparelho de "interpretar-significar" de Freud que falhou em várias gerações.

Esquematicamente, Kaës (2005) destaca que há duas modalidades da transmissão psíquica. Na primeira, transmissão sem transformação, também denominada de transgeracional (Granjon, 2001), existe uma passagem direta de formações psíquicas de um sujeito para outro, sem operações de transformação, são as "rupturas, as falhas, os hiatos não pensados e impensáveis, o nivelamento dos objetos do pensamento, os efeitos da pulsão de morte" (Kaës, 2005, p. 129).

$\mathrm{Na}$ segunda modalidade, transmissão com transformação, também denominada de intergeracional (Granjon, 2001), a realidade psíquica pôde ser trabalhada pela fantasia. Para Trachtenberg (2005), neste tipo de transmissão, está em jogo um trabalho psíquico de elaboração que diz respeito ao grupo e ao sujeito do grupo, "favorecendo transformações e conduzindo a uma diferenciação, a uma evolução entre o que é transmitido e o que é herdado" ( $p$. 121). 
Kaës (2005) considera o mecanismo de identificação como uma das bases essenciais do processo de transmissão da vida psíquica entre gerações. Contudo, nesse processo de identificação, o autor, sustentando-se em Torok e Abraham, observa a necessidade de metabolizar a perda para que o processo de introjeção se realize, porque do contrário o que ocorre é uma incorporação, em que "o sujeito, de um modo mais ou menos fantasioso, faz penetrar e conserva um objeto no interior do seu corpo" (Laplanche, 2004, p. 238).

Outra base de considerável importância para o fenômeno da transmissão da vida psíquica é a "aliança inconsciente" (Kaës, 2005). Para o autor, elas servem para unir uns aos outros em um grupo, em um casal, em uma família ou em um conjunto institucional, referindo-se à elas como o "cimento" da matéria psíquica. De acordo com Fernandes (2004),

\begin{abstract}
Aliança Inconsciente é pensada como uma formação psíquica intersubjetiva construída pelos sujeitos de um vínculo para reforçar, em cada um deles, certos processos, certas funções, ou certas estruturas das quais eles tiram um benefício tal que a ligação que os mantêm junto, toma para sua vida psíquica um valor decisivo. 0 conjunto assim ligado não tem sua realidade psíquica a não ser pelas alianças, contratos e pactos que os sujeitos estabelecem e que seu lugar no conjunto os obriga a manter. Elas estão a serviço de uma função recalcante, e, além disso, de um sobre-recalque, como se fosse um redobramento do recalque, na medida em que elas se manifestam não somente sobre os conteúdos inconscientes, mas sobre a própria aliança (Fernandes, 2004, pp. 12-3).
\end{abstract}

Dentre as "alianças inconscientes", Kaës (2009) assinala que o contrato narcísico (Castoriadis-Aulagnier, 1975) possui um papel central no processo de transmissão psíquica, já que este prescreve cada sujeito que vem ao mundo na sociedade e na continuidade geracional, enquanto portador da missão de assegurar sequência do conjunto social, do qual pertence. Este contrato tem a função de sustentar os investimentos narcísicos de autoconservação de cada sujeito e do grupo. Dessa forma, cada sujeito assume o seu lugar no grupo, significado pelas vozes, pelo conjunto com seus discursos narrativos, valores e mitos fundadores do grupo, sua cultura e as certezas, que serão transmitidos de geração em geração. Assim, o contrato narcísico possibilita o processo de identificação, projeta um futuro à criança e assegura a transmissão da vida psíquica entre as gerações, inscrevendo genealogicamente o sujeito. 


\section{Os Mitos da Família}

No contexto daquilo que se transmite de geração em geração também estão os mitos familiares. Estes, de acordo com Eiguer (2009), aparecem sobre a forma de uma narrativa que implica em uma crença compartilhada pela família. Esta crença advinda de uma interpretação de um fato, um comportamento, um afeto ou um pensamento expresso por algum dos membros foi em algum momento cristalizada em forma de um conhecimento que assumiu o valor de uma verdade absoluta, incontestável.

Antes de consolidar-se como um mito, um fantasma inconsciente se configura e é compartilhado pelo grupo. A formação da crença está associada ao sofrimento psíquico que este fantasma impõe ao grupo que para evitar a confrontação com o mesmo cria a crença como proteção. No entanto, ainda que o mito revele um aspecto negativo, ele também serve para vincular os membros da família, que compartilham do mesmo pensamento, dando a eles o sentimento de identidade e de pertencimento ao grupo, de acordo com o autor.

A maioria dos mitos é inconsciente, ainda que sua narrativa seja consciente e conhecida pelo grupo, porque seu caráter vital e de verdade absoluta não são perceptíveis. Perceber a presença do mito e colocá-lo em questão, portanto, é saudável para a constituição de um indivíduo ou do grupo familiar, mas trata-se de uma tarefa complexa e delicada porque interfere diretamente no sentimento de identidade familiar (Eiguer, 2009).

\section{MÉTODO}

Este artigo objetiva demonstrar a influência e importância da herança psíquica familiar na opção pela não construção de um vínculo amoroso compromissado, a partir da análise de um caso. Escolhemos uma participante da pesquisa $^{2}$ do sexo feminino, com 31 anos na época da entrevista, sem possuir vínculo amoroso compromissado por pelo menos um ano e sem desejo de tê-lo no momento da mesma, sem filhos.

Foi elaborado um roteiro de entrevista semidirigida, que consiste num campo definido de perguntas abertas, no qual o entrevistado pode transitar livremente. O roteiro de entrevista foi composto por quatro partes. A primeira parte referia-se à obtenção de dados gerais dos entrevistados. A segunda parte

\footnotetext{
${ }^{2}$ A escolha do caso ilustrativo se deu pela riqueza do material encontrado na(s) entrevista(s).
} 
visava compreender a dinâmica familiar por meio da história de vida do entrevistado, da história da família, do lugar que ocupava nesta, o tipo de relação que estabelecia com os membros da família de origem e com o legado familiar. A terceira parte foi constituída por temas que visavam compreender características da subjetividade destes mesmos indivíduos (valores, formação da identidade e relação desta com as figuras parentais, importância das atividades profissionais, grau de confiança, hábitos, planos e projetos frente ao futuro, etc.). A quarta parte visava compreender as motivações da opção por permanecer sem um vínculo amoroso compromissado.

Tratou-se, portanto, de uma pesquisa de base qualitativa, cuja estruturação metodológica fundamentou-se no método clínico (Turato, 2003) e psicanalítico (Frosh, 2009) de investigação e cujo tratamento dos dados teve base no referencial psicanalítico individual e de família. O método clínico procura compreender a subjetividade através de uma perspectiva e postura clínica. Esse método científico de investigação, de acordo com Turato (2003), enquanto uma particularização dos métodos qualitativos pretende, a partir de atitudes existencialista, clínica e psicanalítica, propiciar a acolhida das angústias e ansiedades do ser humano, uma aproximação e a valorização dos aspectos emocionais psicodinâmicos.

De acordo com Frosh (2009), a psicanálise enquanto método de investigação pode ser pensada por meio da sua capacidade de doar sentidos e de propiciar um método de investigação que se propõe além do nível racional. Levando em consideração a entrevista semidirigida como instrumento privilegiado de percepção de aspectos inconscientes, o autor aponta que um pesquisador sensível e com capacidade de continência poderá captar a energia subjacente ao que está sendo dito. Sentimentos, pensamentos, fantasias, afetos despertados no pesquisador e no entrevistado no momento da entrevista, poderão ser cuidadosamente, portanto, também tratados como material de análise. Trata-se do modo como se estabelece o vínculo intersubjetivo entre pesquisador e participante, que se puder ser percebido desta forma é capaz de fornecer dados preciosos, muitas vezes ocultos, e poderá contribuir para um conhecimento mais profundo do fenômeno.

A entrevista, segundo Bleger (1980), é um instrumento fundamental do método clínico e uma técnica de investigação científica em psicologia. Para este autor, nessa técnica, por meio da relação estabelecida na transferência os 
determinantes da conduta e da personalidade que não se incluem entre os elementos que o participante poderia trazer voluntária ou conscientemente vão se configurar no campo da entrevista, algo que acrescenta uma dimensão importante para o conhecimento da estrutura da personalidade e do caráter dos seus conflitos.

\section{RESULTADOS E DISCUSSÃO}

Antes de apresentarmos os resultados da análise interpretativa do caso escolhido, cabe ressaltar, conforme aponta Velho (1986), que será apresentado um resumo de história de vida, produto de entrevista gravada que em nenhum momento reflete simplesmente esta gravação nem a vida desta pessoa. De fato, trata-se da produção de um texto que é de nossa responsabilidade enquanto autores de cortes, de interpretações e análises feitas, o que culmina na delineação de um campo de arbitrariedade em que se move o pesquisador-autor.

\section{Patrícia}

Patrícia ${ }^{3}$ é uma moça bastante simpática. Sua entrevista, no entanto, é perpassada por uma "marca" advinda de seu passado, muito clara e incômoda. Aos 31 anos, a separação de seus pais quando ela tinha 8 anos de idade é um assunto que ainda a comove muito. Mais do que isso, ela parece deter uma sabedoria misteriosa a respeito do passado de sua família que embora possa ser transformadora, muito Ihe aprisiona, na verdade.

Na minha família todas as mulheres se separaram... Mãe, avó, bisavó... Tenho uma tia que é casada, mas o casamento dela é horrível. Acho que ela é casada porque é um bom negócio ser casada com o marido dela. O casamento dela é um caos. Então desde criança eu ouço isso: que a vida delas acabou porque elas eram casadas... mas também elas escolheram muito mal: o meu bisavô eu não sei qual era o problema dele, mas com certeza tinha um..., o meu avô morreu de cirrose, ele era alcoólatra e meu pai é viciado em jogo... É complicado você construir uma família com pessoas instáveis, né? Aí desde criança eu já tinha certeza que não queria fazer o mesmo que elas...

O relato de Patrícia sobre sua família suscitou a ideia da presença de uma imago matriarcal forte e impositiva, em que não havia espaço para a existência de homens "bons" porque eles sempre foram vistos como frágeis, dependentes, impotentes, e (por isso) ausentes. Sentimos como uma imago matriarcal

\section{${ }^{3}$ Nome fictício}


impositiva porque a saída que ela encontrou para esse dilema foi simplesmente a de não se apaixonar. Embora consciente, pareceu-nos que essa herança era sem possibilidade de transformação porque ela sentia-se condenada a fazer o mesmo que sua mãe, sua avó, sua bisavó e suas tias fizeram, caso se apaixonasse!

A condenação aparentava versar sobre a escolha de um homem sem caráter que ainda que fosse frágil a faria sofrer porque estava predestinado a não corresponder com as expectativas exigidas por esse grupo de mulheres. Podemos perceber, portanto, a criação de uma fantasia, de um mito familiar, em que uma atribuição de valor positiva ao homem que só se viabiliza pela via do apaixonamento, entendido como "estado de transe", de perda das capacidades de raciocínio, de inteligência, porque na sequência este se mostraria o oposto do imaginado. Portanto, ela parecia pactuar com um mito familiar onde o homem é entendido como o responsável por retirar o bom senso dessas mulheres, ao fazêlas se apaixonar:

(...) eu resolvi que nunca ia me apaixonar. Porque se o problema era esse, né? A minha mãe, a pessoa mais racional da face da terra, como ela aceitou deixar de trabalhar por causa de um homem? Minha avó também é tão firme e foi casar com um bêbado! Deus que me livre! Então eu não queria ter isso para mim...

Ou seja, é como se ela ao longo da vida fosse entendendo que era impossível encontrar um homem bom para se vincular porque estar apaixonada a faria se enganar e escolher erroneamente. Como se ela soubesse que no fundo (pela via inconsciente) algo tendia a levá-la a se interessar por um homem que não seria bom o suficiente e que após "seduzi-la", estragaria a sua vida e a de seus filhos, como seu pai, avô e tios fizeram. Portanto, parece que ela tinha percebido que carregava traços de uma herança psíquica que tendia à repetição, e cremos, em função de algo que não pôde ser elaborado pelas gerações precedentes.

No entanto, ao mesmo tempo, não se apaixonar por outro homem significava também não se desapaixonar do pai. Era nítido no discurso emocionado de Patrícia o quanto ainda sofria com a separação dos pais, principalmente a cada reencontro com seu pai. A sensação que ela deixou foi a de que na sua fantasia a mãe a retirou do pai num momento em que ela não tinha condições de lidar com essa perda, causando um trauma profundo e deixando consequências sérias para a sua vida adulta. 
A hipótese que formulamos é a de que um complexo de Édipo mal resolvido passa pelo viés de um ressentimento com relação a esse pai, por se sentir preterida quando ele vai embora de casa e por sua ausência posterior. Como se ele não tivesse tido forças para lutar contra esse mito familiar de mulheres que se apaixonam e depois rompem com homens ineficazes em suas funções, e Patrícia não o perdoa, inconscientemente, por isso. Com o seu pai tinha que ter sido diferente? Essa talvez fosse a expectativa dela e sua grande frustração. Racionaliza esse sentimento de abandono paternal e a culpa consciente recai sobre a história geracional das mulheres que repetem o mesmo tipo de relação com os homens condenando seus filhos a uma vida sem pai. Trata-se de uma ambivalência, de um conflito que a mantém presa neste nó constitutivo junto ao pai-fantasma.

(...) no caso do meu pai, não acho que foi uma má pessoa, mas ele teve uma vida muito complicada, os pais dele morreram cedo, teve que cuidar dos irmãos... Ele não tem a menor noção do que é família. $\mathrm{Na}$ cabeça dele ele não era um bom exemplo, uma boa influência, então já que ele não podia ajudar, melhor que ele ficasse afastado (...)

O ressentimento inconsciente de ter se sido rejeitada pelo pai parece ter condenado toda uma organização psíquica em função de uma desorganização na base narcísica da identidade. Nesse sentido, ela estaria presa a um vínculo mal resolvido com o pai, a um sentimento de rejeição e de decepção com relação a essa figura e por extensão a todos os homens, onde sente que só lhe resta uma saída para o amor: no encontro com outro homem que repetirá os passos do pai, sobrando-Ihe mais sofrimento e sentimento de rejeição.

- E agora vocês se vêem?

- Mais ou menos, eu não posso ver muito o meu pai. Eu fico nervosa quando encontro com ele. Ele é legal, ele nunca me tratou mal, mas eu não sei...

- Ficou uma coisa muito forte, né? Uma marca.

- É... [fica emocionada]. É com ele eu fico abalada, mas eu vejo ele uma ou duas vezes por ano...

Ela, portanto, encontra-se presa a um vínculo edípico com o pai, pois sente que foi rejeitada por ele em pleno apaixonamento. Ainda busca o entendimento do porquê ele a deixou, atribuindo essa resposta ao mito familiar, tornado sua mãe a grande culpada.

O mais impressionante e fascinante neste caso é a lucidez dessa moça e a consciência que conseguiu atingir sobre esse nó constitutivo e sobre a herança 
psíquica recebida. Supomos que o medo da repetição do modelo geracional de vínculo presume uma herança que foi passada de geração em geração sem transformação e que Patrícia se deu conta disso. No entanto, ainda que seja um pensamento bastante elaborado levando em consideração o mito geracional, se a hipótese de ainda estar presa ao pai no nível edípico estiver correta, esse discurso é também racionalizante como estratégia de defesa. Uma racionalização que a faz perder de vista toda a responsabilidade do pai neste afastamento, utilizando a história de vida dele como um apaziguador e não como um material de onde pudesse advir algum entendimento para a sua ausência, num quadro em que ele tivesse algum nível de responsabilidade. Possivelmente em sua fantasia ela foi a responsável pelo afastamento do pai, por ser ter sido uma menina má, ou por ter sido pouco atraente a ele, dentre outras fantasias que provavelmente guarda sobre si, num processo de construção identitária bastante desvalorizada, em que restaria a dúvida se algum homem poderia verdadeiramente amá-la.

A "saúde mental" que ela diz procurar preservar longe de um vínculo amoroso compromissado, faz pensar numa desorganização interna possível, se tivesse que lidar com essa parte da história. Encarar os fatos e perceber que a mãe não teve toda a culpa como propõe, também significa perder o sentimento de pertencimento ao grupo familiar porque estaria quebrando com o mito que une essas mulheres e seus filhos. Além disso, também dependeria de sua capacidade de elaborar a perda e representá-la, debruçando-se sobre a ausência do pai pelo viés pai-filha. Pensamos que isso poderia ser desorganizador e possivelmente evita um vínculo amoroso compromissado por que este iria lhe propor o trabalho de repensar sua constituição subjetiva, a identidade familiar, a (im)possibilidade de alguém amá-la, de ser atraente, agradável, e mesmo de construir um vínculo amoroso satisfatório.

Hoje em dia Patrícia não tem tempo livre para sair com amigos, se divertir. Ela faz mestrado, trabalha a semana toda, inclusive aos finais de semana e mora com três cachorros que são sua família, enfatiza. Não acha que precisa de um relacionamento estável para ser feliz, o que no contexto atual entende como uma "dor de cabeça" a mais em sua vida.

(...) mas eu não acho que preciso ter um relacionamento estável para ser feliz! Hoje, por exemplo, eu prefiro não ter relacionamento e não ter dor de cabeça, então eu saio, mas para eu resolver namorar com alguém eu penso 800 vezes, principalmente porque eu sei que não 
vou abrir mão de nada na minha vida, porque eu sei que quero ir mais longe na minha vida profissional, quero fazer doutorado, pósdoc, quero ir para fora... E sei que com um relacionamento fica mais difícil, te limita, aí vou ter que pensar que a pessoa vai ficar sofrendo... Então o que não me impede de viajar são meus cães! A pessoa tem que aceitar a minha vida, o que é difícil, eu nunca tenho final de semana livre... Então cada um cuida da sua vida...

Aspectos da contratransferência revelaram sentimentos de admiração por ela, pela força que necessitava fazer para lutar contra a "maré geracional" da qual tem consciência e procura se esquivar, um certo sentimento de carinho e de cuidado do qual a pesquisadora sentiu que ela precisava, além de compaixão pelo modo como se envergonhava da "desestrutura" da sua família, de sua história. Ela pareceu realmente muito fragilizada. Uma organização psíquica precisando de reparos para ganhar integridade e uma natureza mais consistente.

Pensamos que quebrar com o mito geracional de mulheres fortes e homens inúteis é desorganizador porque embora tenha sempre culpado sua mãe por ter tido um relacionamento marcado de mágoas até o presente, foi ela quem não se ausentou de sua vida e é a figura mais próxima. O vínculo com a mãe e com as mulheres da família lhe oferece um lugar nesta família, uma identidade. Contudo, sendo este o processo de subjetivação em que a apropriação da herança possibilita a construção de uma história criativa e inovadora, desfazendo-se das alianças inconscientes e alienantes, podemos pensar que no caso de Patrícia esta se encontra ainda presa num processo de repetição.

Podemos também pensar num contrato narcísico parental que ficou abalado em função do desaparecimento do pai, e da ausência e dos conflitos com a mãe, deixando-a sem rumo, muito mais ligada a um passado incompreensível, num deserto sem futuro porque por enquanto ainda só sabe o que não quer para o seu futuro. Para Patrícia tudo ainda gira em torno dos pais. No final da entrevista ela relata à pesquisadora que ela iria dizer que "tudo era problema dos meus pais". Ou seja, pela via da projeção, podemos entender que isso é o que ela no fundo realmente pensa. Patrícia precisa elaborar suas perdas para poder seguir em frente.

Não que eu seja "master" apegada com as coisas materiais, mas é complicado... A gente tinha de tudo, judô, natação, toma quantos litros de leite você quer. Você não tem noção do que é não ter! E daí de um dia para o outro você não tem nada, mas o que eu mais sentia falta era da companhia deles [dos pais]...

Foi, sobretudo, a presença e o carinho dos pais que perdeu, o que torna o processo de representação da falta muito mais delicado já que afetou, como 
supomos, a base narcísica de sua identidade. De acordo com CastoriadisAulagnier (1975) será por meio do contrato narcísico que a criança em formação se encarregará dos projetos dos pais para dar continuidade à família e planejar seu próprio futuro. Sem a elaboração destas perdas, não é possível para Patrícia, supomos, imaginar projetos futuros que sejam da ordem do compartilhamento. Ela sabe que existe uma saída para seu dilema quando diz que a mãe, as tias e a avó escolheram errado, pois do contrário nem teria percebido o "erro". Até porque seus pais se casaram novamente e, apesar de passar quase despercebido em seu relato, eles estão bem em seus novos relacionamentos. Assim, é como se ela realmente não estivesse pronta para um futuro possível ao lado de alguém. No final da entrevista ela assume que se algum dia vier a ter outro relacionamento estável será preciso que esteja apaixonada, porque percebeu que sem paixão não tem sentido, revelando também a possibilidade e o desejo guardado, dito somente ao final da entrevista pelo seu caráter terapêutico, imaginamos, já que realmente foi uma experiência intensa e significativa tanto para pesquisadora como para a participante.

\section{CONSIDERAÇÕES FINAIS}

Embora as condições contemporâneas de existência favoreçam a estruturação de subjetividades muito mais autocentradas e individualistas, entendemos que os fatores psíquicos individuais e de origem geracionais também têm uma importante raiz na configuração pela não construção de um vínculo amoroso compromissado, como visto no caso de Patrícia. Desta forma, salientamos a importância do trabalho de elaboração e de apropriação do que recebemos em termos de vida psíquica de nossos ancestrais para a constituição da subjetividade e dos laços amorosos, já que estes exigem uma disponibilidade para estar com o outro que passa pela ordem da aceitação da alteridade (Eiguer, 2008). Quanto mais livre esta alteridade estiver de projeções advindas do passado psíquico, herdado, melhor para a construção destes vínculos.

No caso de Patrícia, ela parece paralisada diante de uma construção defensiva que a salva da vivência de vínculos amorosos verdadeiros e profundos por ser altamente desorganizadora, já que ainda encontra-se muito envolvida com conflitos herdados dos familiares, como se sem isso the fosse impossível seguir adiante. Uma herança psíquica incapaz de ser transformada, que provoca falhas na organização narcísica, não favorece o impulso para ser transmitida de 
forma criativa. Poderíamos, então, concluir que isso não estimularia o indivíduo a se comprometer com as gerações posteriores, tomando como uma das motivações inconscientes para esse tipo de opção amorosa descompromissada da atualidade.

\section{REFERÊNCIAS}

Bleger, J. (1980). A entrevista psicológica. In J. Bleger, Temas de psicologia: entrevista e grupo. (pp. 7-44). São Paulo: Martins Fontes.

Castoriadis-Aulagnier, P. (1975). La violence de l'interprétation. Le pictogramme et l'énoncé, Paris: PUF.

Eiguer, A. (2008). Jamais moi sans toi. Paris: Dunod.

Eiguer, A. (2009). Les mythes de la famille et du thérapeute familial et leur déconstruction. Le Carnet PSY, 3 (134), 31-35.

Féres-Carneiro, T. (2005). Conjugalidade dos Pais: possíveis influencias no projeto de casamento dos filhos. In Simpósio Nacional de Psicologia Social e do Desenvolvimento $X$ Encontro Nacional PROCAD-Psicologia/CAPES. Violência e Desenvolvimento Humano: Textos Completos, pp. 89-97.

Fernandes, M. I. A. (2004). Algumas reflexões sobre a negatividade na construção dos laços sociais [Versão eletrônica]. Vínculo, 1 (1), 9-16.

Freud, S. (1921-2006). Psicologia de Grupo e a Análise do Ego. In S. Freud, Além do princípio de prazer psicologia de grupo e outros trabalhos. Edição Standard Brasileira das Obras Psicológicas Completas de S. Freud, Vol. XVIII. (pp. 79-154). Rio de Janeiro: Imago.

Frosh, S. (2009). O Lugar da Psicanálise no Campo da Psicologia Social. Aulas ministradas no Instituto de Psicologia nos dias 25 e 27 de agosto, 01, 03 e 04 de setembro de 2009.

Granjon, E. (2001). A elaboração do tempo genealógico no espaço do tratamento da terapia familiar psicanalítica In O. B. R. Correa (Org.), Os avatares da transmissão psíquica geracional. (pp. 17-43). São Paulo: Editora Escuta.

Haesler, L. (1992). De la transmission transgénérationnelle du traumatisme. Journal de la Psychanalyse de L'enfant, 9, 132-147.

Kaës, R. (1993). Transmission de la vie psychique entre générations. Paris: Dunod. 
Kaës, R. (2001). O sujeito da herança. In R. Kaës; H. Faimberg et al. (Orgs.), Transmissão da vida psíquica entre gerações (pp. 9-25). São Paulo: Casa do Psicólogo.

Kaës, R. (2005). Espaços Psíquicos Compartilhados: transmissão e negatividade. São Paulo: Casa do Psicólogo.

Kaës, R. (2009). La transmission de la vie psychique et les contradictions de la modernité , In Marcel Sassolas Transmissions et soins psychiques (pp. 2135). Érès Hors collection.

Kaës, R. (2011). Um singular plural: a psicanálise à prova do grupo. São Paulo: Edições Loyola.

Laplanche, J. (2004). Vocabulário de Psicanálise. Laplanche e Pontalis. São Paulo: Martins Fontes.

Levine, H. B. (1982). Toward a psychoanalytical undertanding of children of survivors of Holocaust. Psychoanalytical Quarterly, LI, 70-92.

Magalhães, A. S. \& Féres-Carneiro, T. (2004/dezembro). Transmissão psíquicogeracional na contemporaneidade. Psicologia em Revista, Belo Horizonte, 10 (6), 243-255.

Passos, M. C. (2007, novembro). A constituição dos laços na família em tempos de individualismo. Mental, V, 5(9), 117-130.

Puget, J. ; Kaës, R et al (1989). Violence d'État et psychanalyse. Paris: Dunod.

Schacht, L. (1977). Découverte de I'historicité. Nouvelle revue de psychanalyse, 15, 69-79.

Stern, J. (1986). Quarante ans après à Beer-Scheba. In P. Fédid, J. Guyotat et al, Mémoires, transferts. Paris: Ècho-Centurion.

Trachtenberg, A. R. C. (2005). Trauma, Transgeracionalidade e Intergeracionalidade: uma transformação possível. In A. R. C. Trachtenberg et al, Transgeracionalidade: de escravo a herdeiro: um destino entre gerações (pp. 119-129). São Paulo: Casa do Psicólogo.

Turato, E. R. (2003). Tratado da metodologia da pesquisa clínico-qualitativa. Petrópolis: Vozes.

Velho, G. (1986). Subjetividade e Sociedade: uma experiência de geração. Rio de Janeiro: Jorge Zahar Editor. 
Contato: sandra.zanetti@gmail.com, isagomes@ajato.com.br

Recebido em: 31/05/2012

Revisado em: 07/06/2012

Aceito em: 20/06/2012 